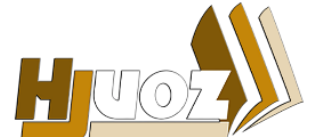

hjuoz.uoz.edu.krd p-ISSN: 2410-7557
كَّوارا زانستيّن مروّقايهتى يا زانكوّيا زاخوّ

مجلة العلوم الانسانية لجامعة زاخو

Humanities Journal of University of Zakho (HJUOZ)

Vol. 5, No. 3, pp. 754-767, Sept.-2017

\title{
تأثير أسلوبي التمايز التنافسي المباشر وغير المباشر في تعلم بعض المهارات الهجومية في كرة اليد
}

مؤيد كمال الدين عزالدين، سعدي عمر يوسف و ابراهيم موسى ابراهيم

سكول تربية الأساس، جامعة دهوك، اقليم كردستان - العراق.

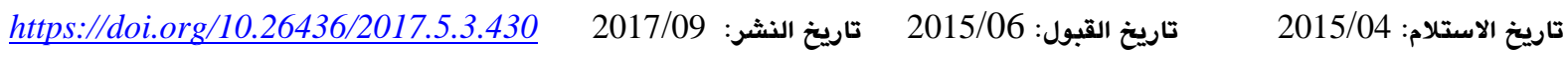

الملخص:

تهدف هذه الدراسة إلى الكثف تاثير اسلوبي التمايز التنافسي( المباشر وغير المباشر ) واسلوب العرض التوضيحية (التقليدي) في

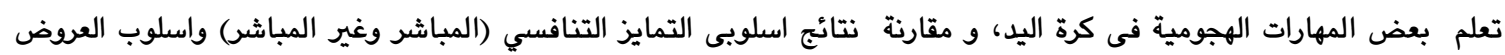

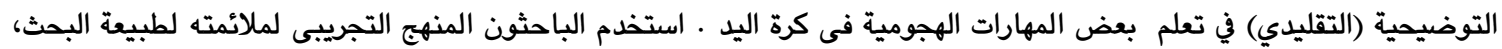

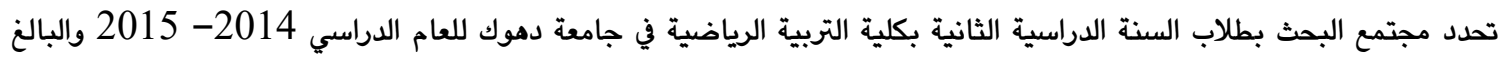

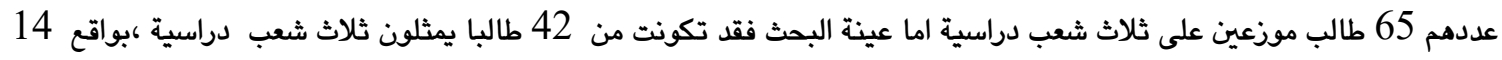
طالبا لكل مجموعة تم اختيارهم بطريقة عشوائيا بعد استبعاد عدد من افراد مجتمع البحث وذلك لعدم تجانسهم مع بقية افراد العينة، ويعد التكافؤ بين مجموعتي عينة البحث تم وضع برنامجين تعليميين للمهارات المختارة قيد البحث و تم اعتماد البرنامجين التعليميين

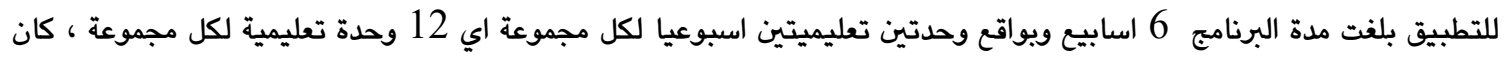
زمن الوحدة التعليمية الواحدة 90د تم توزيعها وفقا لمحتوى الوحدة وتمت معالجة البيانات إحصائيا باستخدام برنامج (SpsS)

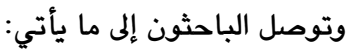
1- كان لاسلوبي ( التمايز المباشر وغير المباشر) واسلوب العرض التوضيدية ( التقليدي) تاثير ايجابي في تعلم بعض المهارات الهجومية بكرة اليد.

2.حققت المجموعة التجريبية الثانية التي استخدمت الاسلوب التنافسي المباشر مستوى افضل من المجموعة التجريبية الاولى التي استخدمت الاسلوب التنافسي غير المباشر والمجموعة الثالثة التي استخدمت الاسلوب العرض التوضيحية (التقليدي) في تعلم بعض التهريان المهارات الهجومية بكرة. الكلمات الدالة: اسلوبي التمايز التنافسي، المهارات الهجومية، كرة اليد، كلية التربية الرياضية، جامعة دهوك. والتدرج بها على ضوء قدراتهم . ان التدريس الذي يخطط بعيداً عن

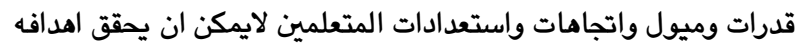
مهما كان يمتلك من جودة و اتقان · ( الشافعي 2009 ، 202 ، 92 ). في حين ان تنويع التدريس او تمايزه للطلبة يمثل في الواقع الاستجابة الصحيحة لحاجات المتعلم و قدرته واهتماماته ، وحيث ان للطلبة قدرات واستعدادات و دوافع مختلفة فان التعليم المتمايز توفر فرص

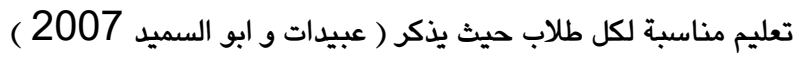

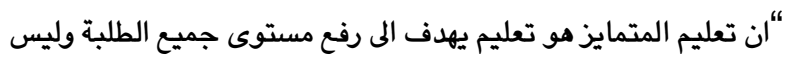
الطلبة الذين يواجهون مشكلات في التحصيل " (عبيدات وابو السميد، . (107، 2007

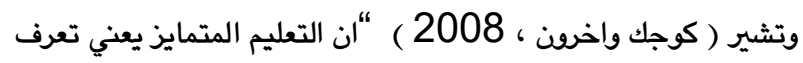
احتياجات المتعلمين المختلفة و معلوماتهم السابقة و ميولهم ثم الاستجابة لذلك في عملية التدريس " ( كوجك و اخرون، 2008 ، 25

\section{1. المقدمة وأهمية البحث}

ان العالم يعيش عصر تقدم علمي مذهل ، ففي كل مجال حقق العلم وثبة كبيرة ،ولا يزال يثب في اضطراب مستمر لتحقيق تقدم اكبر ،وكان للرياضة نصيب من هذا التقدم ،حيث لعب طموح علمائها دورا اساسيا فى الاعتماد على علوم جدية ليكون منها المنطلق للتقدم . ولما كان التعلم يتاثر الى حد كبير بالاساليب والطرائق التدريسيية التى يتبعها المعلم فان التعلم الذى يقوم على اساس التجريب ،والتطبيق ينتقل اثره اسهل من التعلم الاصم الذى يلقن فيه المتعلم فقط مجموعة

من المعرفة لا يعرف فوائد تعلمها ، تشكل الفروق الفردية بين المتعلمين حالة تحتاج الاهتمام بها و مراعاتها في مراحل اكتساب المهارة و التقدم بالاداء ، و ذلك لاكمال عملية التعلم و الاستفادة من قدرات الافراد اذ انها تساعدنا في تنظيم مفردات المنهج التعليمي بما يلائم متطلبات البيئة التعليمية و اختيار المهارات الحركية 
(2008 ) ومن منطلق الدراسات النظرية ،واهمية دراسة الجانب النفسى ،فى انجاز العملية التعليمية ،نجد انه من العبث انكار الفروق الفردية عن المتوسط الجماعى اثناء التطبيق العملى ،لان التعلم الذى لايؤتى ثماره،يجعل المتعلم عاجزا عن مسايرة الاغلبية من زملائه ،مما يسبب ذلك اضرار معنوية بالاضافة الى انه جهد شبه ضائع لمن يقوم بالتدريس .وفي ضوء ما سبق تكمن أهمية البحث في دراسة أسلوبين من التمايز التنافسي المباشر و غير المباشر و مو مقارنته بأسلوب العروض التوضيحية ( التقليدي ) في تعلم بعض المهارات الهجومية بكرة

1.1 على الرغم من تعدد طرائق التدريس وأساليبها سواء كانت مباشرة او غير مباشرة يبقى البحث عن الأسلوب الأفضل الذي يلاءم الفعالية

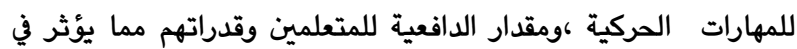
الاقتصاد بالجهد ،واستثمار وقت التعلم الأكاديمي. وقد لاحظ الباحثون من خلال خبرتهم الميدانية عدم تنوع الأساليب التعليمية لذا وجدوا ضرورة الدراسة والبحث للنهوض بالطلبة لمستويات ذات فعالية والتعرف على تاثير بعض الاساليب للوصول الى تعلم افضل ،من المنطلق السابق وجدوا ان المشكلة تنحصر فى الاتي : ان تقسيم الطلبة الى الشعب يتم عن طريق القرعة ، أو يتم إدراجهم

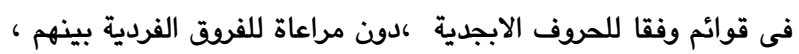
كما ان بعض القائمين بالتدريس يستخدمون أساليب تقليدية مكونه من مجموعة تدريبات مكررة لفترات طويلة ، مما يسبب فقدان التدريبات لعنصر التشويق والاثارة، أوصعوية تطبيق لبعض التدريبات

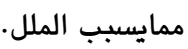

الأمر الذي يشير لوجود مشكلة تتطلب إيجاد حلول مناسبة لها ، ومواقف تنافسية أثناء التطبيق للدروس العملية وذلك باستخدام أساليب تتحدى جهد الطالب الفكري ، وشحذ الطاقة وتنمية الارادة اللازمة فى تعليم المهارات المدرجة داخل المقرد الدراسي لطلبة المرحلة الثانية بالكلية وان يعتمد المدرس فى تدريسه على المنافسات الفردية والجماعية، وتدريبات ،ومواقف تعليمية تحتوى على عناصر الموقف التعليمى في الملعب من منافسات ، وزملاء ، وأدوات ،وقواعد اللعب المبسطة ،مذه القوى تجعل عملية التعلم مباشرة ،وذات معنى لدى

وقد ارتأى الباحثون ضرورة استخدام أساليب تدريسية متنوعة وقد

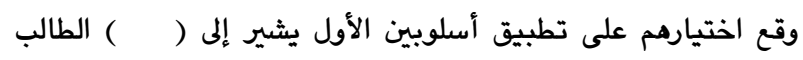
بالضعيف ( ميزة ) بتقدمه على الطالب المتقدم (الجيد) بفارق في التكرارات او الزمن أو المسافة و ذلك لتكون الفرصة متكافئة بينهم في التنافس المباشر و غير المباشر ( أسلوب التمايز التنافسي ) ، بينما الأسلوب الثاني فهو يعتمد على المدرس في جميع القرارات العروض التوضيحية ( التقليدي) في تطوير بعض مهارات الهجومية بكرة اليد .
ويشير عبدالكريم (1996 ) و زغلول و اخرون ( 2002 ) بانه لايوجد اسلوب واحد يمكن ان يسهم فى التنمية الكاملة لمتعلم ،كما لا توجد طريقة واحدة يمكن ان نعتبرها افضل الطرق فى التدريس ،فالمدرس الكفء هو الذي يختار منها ما يتناسب والموقف التعليمي لامكان التاثير في دافعيه المتعلمين ،وتعليمهم بطريقة فعالة مجدية تكسبهم بصيرة ، وفهم اكبر مما يساهم في انجاز خبرة تعليمية عميقة

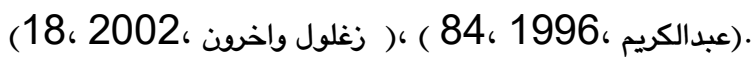
ولما كانت كرة اليد من الالعاب الجماعية التى لا يتطلب الاداء الحركى فيها تكوين انماطا سلوكية جامدة بل تتطلب قدرة على تغيير السلوك ، وتعديله وفقا لمواقف اللعب المتغيرة اثناء التعلم لذا كان من الاممية تنظيم الطرق ، و الاساليب للوصول لتحقيق الاهداف المرجوة ، ولقد

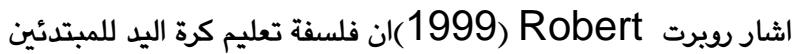
يمكن تلخيصها فى ثلاثة اهداف : تحقيق المهارات الحركية بصورة جيدة والتدريب عليها بعامل التشويق والبعد عن الملل ،والتاكد من

التغذية الراجعة اثناء الممارسة (1999,34 Robert ولقد اتفقت آراء العديد من الذبراء دبور ( 1996) وعبدالله (2004)على ان البراعة فى تعليم كرة اليد تتركز فى تمكن الافراد من ادراك وحدة الصورة الكلية الجماعية ، ويتم ذلك من خلال الممارسة الفعلية المبسطة للعبة فى اشكال تنافسية ، تعمل على تنميه المهارات

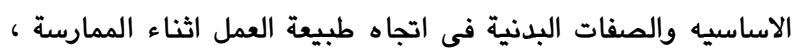
نظرا لان المتعلم اثناء المنافسة يمر بمواقف متنوعة ،ومتغيرة، ومطلوب ان يكيف مهاراته ،وقدراته لحل هذه المواقف .( دبور ،1996

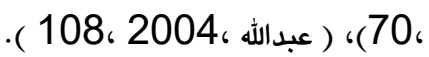

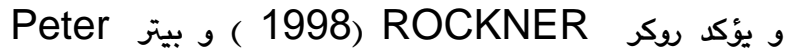

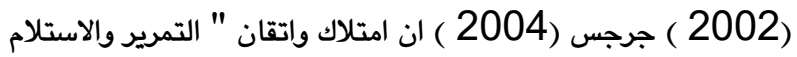

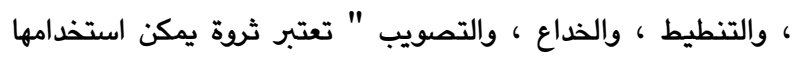
باشكال مختلفة عنما تؤدى بالدقة والسرعة المطلوبة ولتحقيق الهدف منها يجب تعلمها واكتسابها مبكرآ بقدر الامكان . ROCKNER

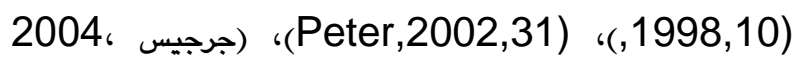

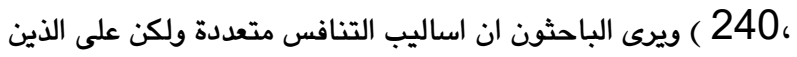

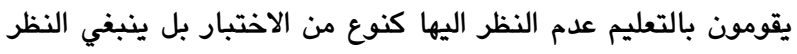

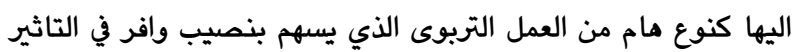
على تنمية وتطوير مهارات وقدرات المتعلمين · ولقد اثيرت العديد من الدراسات التربوية باستخدام المنافسات فى مجال الالعاب الجماعية ، ومن خلال المسح المرجعي للدراسات التى اجريت فى مجال كره اليد ،والتي اثبتت نتائجها ان الافراد الذين يستقبلون خبرات النجاح اثناء المنافسة افضل تقدما بالمقارنة مع الافراد الذين يستقبلون خبرات النجاح بدون منافسة وهذد ما أكدته دراسات كل من سلامة ( 1993 ) جبر وابو بكر (1993 ) ومحمد لأدرات وعزت (1998 ) و عبدالسلام ( 1999) و المفتي (2000) و رضا ( 
وشرحها ، وتصديح الأخطاء ، و الأداء ،والتوجيه وإلا رشاد ،ودود الطالب في الأداء ، والمتابعة ، والإطاعة .

2. الدراسة النظرية والدراسات السابقة

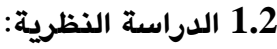

1.1 .2 المنافسة أسلوب من أساليب التعلم: تعد المنافسة

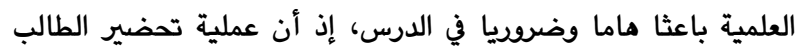
اليومي ومشاركته في الدرس وحدها لا تنطوي على أي معنى ولكنها تكتسب معناها عند ارتباطها بمستوى أداء الطالب من اجل الحصول على أفضل مستوى يمكن تحقيقه في المنافسة العلمية، وفي ضوء هذا تكون المنافسة العلمية خير عون لتقويم نتائج العملية التعليمية وتساهم بالتالي بنصيب وافر في إنماء وتطوير مهارات وقدرات الطالب. (الدوسكي 2003، (2003، (11)

2.1 .2 أنواع المنافسة: يعتمد استخدام المنافسة على نوع النشاط الرياضي الذي يمارسه الفرد وعلى المواقف التي يتطلبها هذا النشاط

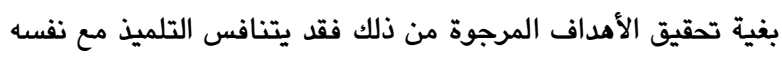
او مع تلميذ آخر حسب متطلبات الأداء او اللعبة، وتوجد أساليب متعددة للتنافس واختلف الخبراء في تقسيمها فمنهم من قسمها الى ثلاثة

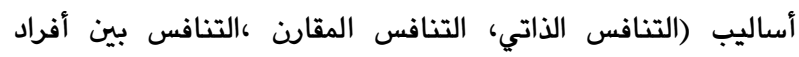

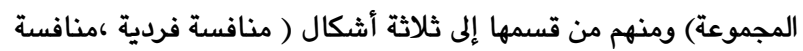

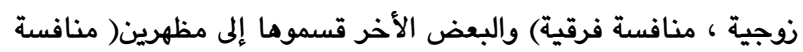

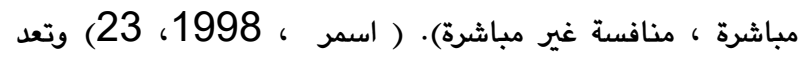

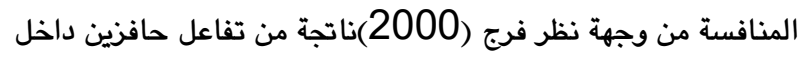

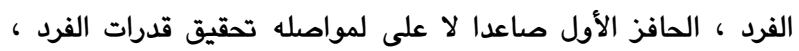
والحافز الثاني لمواصله تقييم قدراته من خلال تعاونه مع زملائه ، لقافئ ومنافسيه وكلما كان الحافزين داخل الفرد فان تنافسه سوف يصبح

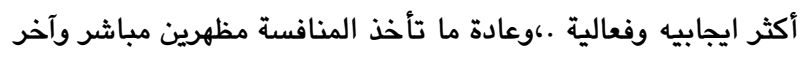

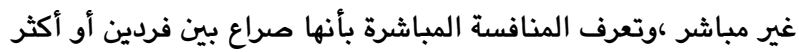
يناضلون من اجل هدف ما ،بينما المنافسة غير المباشرة عندما يجتهد الفرد لتحقيق هدف معين ، ولا يعتمد نجاح او فشل حصوله على هذا

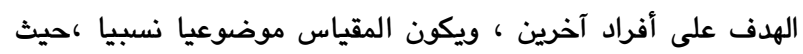

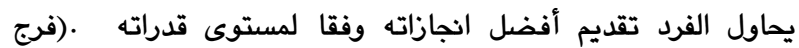
62 - 2000،

3.1 .2 المهارات الأساسية بكرة اليد: تعد المهارات الأساسية

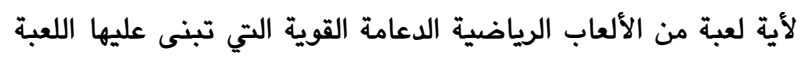
وكرة اليد من الألعاب الجماعية التي يحتاج فيها اللاعب إلى حالة تدريبية (بدنية، مهارية، خططية، نفسية) لمواجهة المنافسة الرياضية، الأمر الذي يجعل كل الاهتمام بإعداد اللاعب على جانب كبير من الأممية.

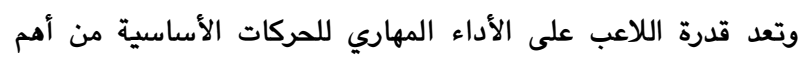

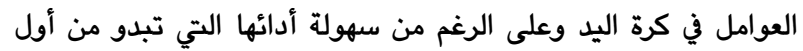

و من هنا تحددت مشكلة البحث في محاولة الإجابة على التساؤل الآتي" ما تأثير اسلوبى التمايز التنافسي و العرض التوضيحية ( التقليدي )

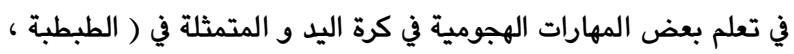

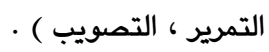

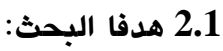

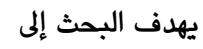
أ. الكشف عن تأثير اسلوبي التمايز التنافسي( المباشر وغير البي

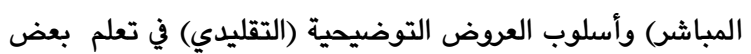

$$
\text { المهارات الهجوميةفى كرة اليد . }
$$

ب. مقارنة نتائج اسلوبى التمايز التنافسي ( المباشر وغير المباشر)

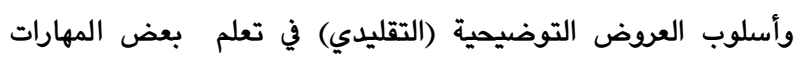
الهجوميةفىكرةاليد 3.1

1- و جود فروق ذات دالة إحصائية بين نتائج الاختبارات القبلية

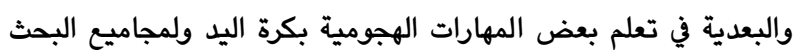
الثلاثة ولمصلحة الاختبارات البعدية. 2- ل اتوجد فروق ذات دلالة إحصائية في نتائج الاختبارات البعدية بين مجاميع البحث الثلاثة في تعلم بعض المهارات الهجومية بكرة اليد. 4.1 المجال البشري : طلبة المرحلة الثانية بكلية التربية الرياضية /جامعة المجال ألزماني : المدة من 2015/1/12 2015/2 المجال المكاني : القاعة الداخلية لكلية التربية الرياضية / جامعة دهوك 5.1 1- الطالب المتقدم :هو الحصول على 65٪ من مجموع درجاته فى القدرات الحركية والمهارية (قيد البحث) 2- الطالب غير المتقدم : هو الحصول على 50 ٪ ٪ فاقل في مجموع درجاته فى القدرات الحركية والمهارية ( قيد البحث ) 3- أسلوب التمايز التنافسي هو احد" الأساليب التي تستخدم مبدأ عدم التكافؤ أثناء التنافس بين الطلبة" ويتم ذلك من خلال : فرض عبئ إضافي على الطالب المتقدم حتى تصبح فرص الكسب متكافئة أثناء المواقف التعليمية (فى المتغيرات قيد البحث ) .أو بالتقدم بفارق في التكرارات ، او الأزمنة ،او المسافات " للطالب غير المتقدم

4- أسلوب العرض التوضيحية (التقليدية ) هو احد "الأساليب التي يتخذ فيها المعلم جميع القرارات "من تخطيط ، وتنفيذ ، وتقييم ، وتغذية راجعة، وعرض المهارة المراد أدائها ، 
إن أساليب التدريس الثلاثة هي أساليب فعالة في تعليم المبتدئين فن أداء المهارات الحركية بكرة القدم. إن استخدام أسلوب المنافسات في تدريس المهارات الحركية بكرة القدم أثرا إيجابيا في اكتساب الطلاب لهذه المهارات. 3. إجراءات البحث

1.3

استخدم الباحثون المنهج التجريبي لملائمته لطبيعة البحث . 2.3 مجتمع البحث وعينته:

تحدد مجتمع البحث بطلاب السنة الدراسية الثانية بكلية التربية الرياضية في جامعة دهوك للعام الدراسي 2014- 2015 والبالغ عددمم 65 طالب موزعين على ثلاث شعب دراسية . اما عينة البحث فقد تكونت من 42 طالبا يمثلون ثلاث شعب دراسية ،بواقع 14 طلاب لكل مجموعة تم اختيارهم بطريقة عشوائيا بعد استبعاد عدد من افراد مجتمع البحث وذلك لعدم تجانسهم مع بقية افراد

$$
\text { العينة والمستبعدون هم : }
$$

لاعبو منتخب الكلية والأندية الرياضية بكرة اليد.

الطالبات لان حدود البحث تقتصر على عينة من الذكور فقط. الطلبة المشتركين في تقنين المتغيرات قيد البحث والمصابين. ثم ثم توزيع أسلوب التدريس ( التنافسي غير المباشر،التنافسي المباشر ) بطريقة عمديه وذلك لكي يستطيع الباحثون التفريق بين الطالب الجيد و الضعيف .. ولايمكن توزيع اسلوبى التدريس بشكل عشوائي ـ لان المطلوب هو التمايز الطالب الضعيف عن الطالب الجيد

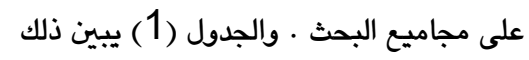

وهلة، إلا أنها تتطلب بذل جهد كبير في إتقانها لما يفرضه قانون اللعبة

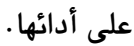

2.2 الدراسات السابقة:

1.2 .2 دراسة الخياط (1997)

" اثر استخدام أسلوبي التنافس الذاتي والمقان في تعليم بعض

المهارات الحركية بكرة القدم "

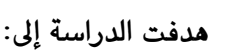

-

والتنافس المقارن والتقليدي) في تعليم بعض المهارات الحركية

بكرة القدم ·

- المقارنة بين استخدام أساليب التعليم (التنافس الذاتي والتنافس المقارن والتقليدي) في تعليم بعض المهارات الحركية بكرة القدم.

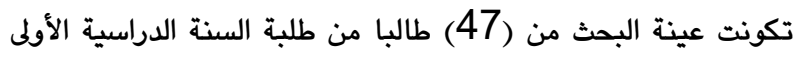
بكلية التربية الرياضية بجامعة الموصل اختيروا عشوائيا من بين الشعب من

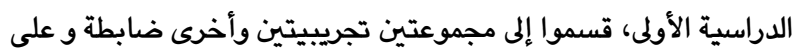

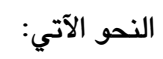

- المجموعة الأولى: استخدمت أسلوب التنافس الذاتي (تجريبية أولى). - المجموعة الثانية: استخدمت أسلوب التنافس المقان (تجريبية ثانية) - المجموعة الثالثة: استخدمت الأسلوب التقليدي (ضابطة) . وتم إعداد برنامج تعليمي خاص بالمادة التعليمية وذلك خلال مدة إجراء التجربة ثم أجريت بعد ذلك الاختبارات البعدية واستخدم الباحث اختبار (ت) وتحليل التباين باتجاه واحد واختبار اقل فرق معنوي L.S.D. وقد توصل الباحث إلى الاستنتاجات الآتي

\begin{tabular}{|c|c|c|c|c|c|}
\hline أسلوب التدريس & عدد أفراد العينة النهائي & المستبعدون & العدد الكلي & المجموعة & الشعبة \\
\hline التنافس غير المباشر & 14 & 14 & 28 & التجريبية الأولى & \\
\hline التنافس المباشر & 14 & 12 & 26 & التجريبية الثانية & \\
\hline التقليدى & 14 & 14 & 28 & الضابطة & \\
\hline
\end{tabular}
الجدول (1): يبين عدد أفراد عينة البحث حسب مجاميع البحث وأسلوب التدريسي

الطول مقاسا بالسنتيمتر.

3.3 تكافؤ مجموعات البحث:

الكتلة مقاسا بالكيلو غرام. وتم استخدام تحليل التباين باتجاه واحد للتحقق من تكافؤ المجموعات

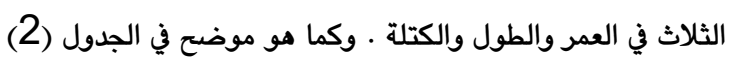
تمت عملية التكافؤ بين مجموعات البحث لضبط المتغيرات الآتية: العمر الزمني مقاسا بالسنة.

\begin{tabular}{|c|c|c|c|c|c|}
\hline ف المحتسبة & متوسط المربعات & مجموع المربعات & درجات الحرية & ممادر الاختلاف & الاحصائية \\
\hline \multirow[t]{2}{*}{0.567} & 1.595 & 3.190 & 2 & بين المجموعات & \multirow[t]{2}{*}{ العمر / سنة } \\
\hline & 2.815 & 109.786 & 39 & داخل المجموعات & \\
\hline \multirow[t]{2}{*}{1.999} & 69.595 & 139.190 & 2 & بين المجموعات & \multirow[t]{2}{*}{ الطول / سم } \\
\hline & 34.815 & 1357.786 & 39 & داخل المجموعات & \\
\hline \multirow[t]{2}{*}{1.040} & 34.357 & 68.714 & 2 & بين المجموعات & \multirow[t]{2}{*}{ الكتلة /كفم } \\
\hline & 33.035 & 1288.357 & 39 & داخل المجموعات & \\
\hline
\end{tabular}
الجدول (2): يبين تحليل التباين لمجاميع عينة البحث في العمر والطول والكتلة 
لذلك ينبغي تحديد المتغيرات والسيطرة عليها من خلال تمكن الباحثين من السيطرة على المتغيرات الداخلية وهي ( ظرفف التجربة ، ادوات القياس، فروق الاختبار، التاركون للتجربة ) وعلى المتغيرات الخارجية وهي خلو ويعد التجربة من الاخطاء. 7.3 - 7.3 من اجل الوصول الى الحقائق العلمية استعان الباحثون بعدد من الوسائل لجمع البيانات وهي . تحليل المحتوى المصادر استمارة استبيان الاختبارات 8.3 الاجهزة والادوات المستخدمة: 1- ساعة توقيت الكترونية عدد 2 2- - - جهاز لقياس الوزن 3- كرات يد عدد 12 4- كرة طبية وزنه 800 غم عدد 1 -5 - 5 كافرة 6- شريط قياس بطول 30 م م

9.3 التجرية الاستطلاعية للاختبارات المهارية: اجرى الباحثون تجربة استطلاعية في 2014/12/15 ويمصاحبة الفريق المساعد* على مجموعة من الطلاب ومن نفس مجتمع البحث من

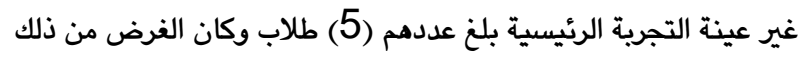
ما يأتي : التعرف على الصعويات والمعوقات التي تواجه الباحثون. التعرف على الوقت المستغرق في تنفيذ الاختبارات. اختبار كفاءة الاجهزة والادوات.

تعرف فريق العمل على طبيعة تطبيق الاختبارات.

10.3 التجرية الاستطلاعية الاولى للبرنامج التعليمي الخاص بالاسلوب التنافسي المباشر: قام الباحثون بالتجربة الاستطلاعية الاولى في يوم 12/18 2014على عينة من مجتمع البحث مكونة من 10 طلاب وعلى مهارة

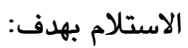

1- التأكد من مدى صلاحية البرنامج التعليمي للتطبيق.

2- معرفة مدى استجابة الطلاب لتنفيذ محتويات الوحدة التعليمية المقترحة على وفق الأسلوب التنافس المباشر. 3- معرفة تكرار ومناسبة الزمن المستغرق في التنفيذ ، اكتشاف الصعويات التي تواجه الباحثون أثناء التطبيق لكل جزء من أجزاء المهارة. 4- إعطاء صورة واضحة لمدرس المادة المكلف بما هو مطلوب منه . * يتكون الفريق المساعد :
قيمة (ف) الجد ولية ( 3.23 ) عند نسبة خط > 005 ودرجة الحرية ( 39-2 ) يتبين من الجدول (2) ما يأتي: عدم وجود فروق ذات دلالة إحصائية بين طلاب المجموعات الثلاث في كل من العمر والطول والكتلة مما يشير الى تكافؤ مجموعات البحث في هذه المتغيرات. 4.3 تصديد عناصر اللياقة البدنية المؤثرة في تعلم المهارات

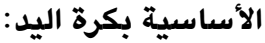
اعتمد الباحثون على الدراسات السابقة التي تناولت أهم عناصر اللياقة البدنية المؤثرة في تعلم بعض المهارات الهجومية في كرة اليد والاختبارات

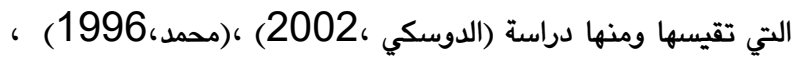
( الخياط، 1995) ،( شيت، 1994) والتي حددت العناصر الآتية:

$$
\text { القوة الانفجارية للأطراف السفلى الانفجارية للأطراف العليا }
$$

الدقة والتوافق والتي ثم قياسها من خلال الاختبارات الآتية:

اختبار الوثب الطويل من الثبات لقياس القوة الانفجارية للأطراف

السفلى

اختبار رمي كرة طبية وزتها (800غم ) لا بعد مسافة لقياس القوة

الانفجارية للأطراف العليا

اختبار تمرير الكرة على الحائط لقياس الدقة والتوافق لافيه

ؤرلا

5.3 تحديد اختبارات المهارات الهجومية المختارة: عمد الباحثون إلى تصميم استمارة استبيان (ملحق1) وعرضها على عدد من المختصين (ملحق3) في لعبة كرة اليد والاختبارات والقياس والتقويم بهدف تحديد الاختبارات لقياس المهارات الهجومية التي شملها البحث والتي تم تحديدها على وفق مفردات مادة كرة اليد المنهجية لطلاب السنة الدراسية الثانية في كلية التربية الرياضية والتي اشتملت على ( التمرير، الطبطبة، التصويب ) ويعد جمع البيانات وتفريغها تم تحديد الاختبارات التي حصلت على اكثر التكرارات وهي: 1- المناولة الطويلة ودقة توجيه الكرة من مسافة (30م)

2- اختبار الطبطبة المستمرة في اتجاهات متعددة الخياط والصيالي، 3- اختبار دقة التصويب من القفز من مسافة (7 م ) · ماسماعيل و حسنين، 2002، 105-106) 6.3 يتضمن البحث المتغيرات الاتية: 1- المتغير التجريبي ( المستقل ) وتمثل اسلوبي التنافسي المباشر الاتير وغير المباشر. 2- المتغير التابع وهو تعلم بعض المهارات الهجومية بكرة اليد. 


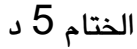

وقد اتبع الباحثون الخطوات الآتية في تطبيق تجربة البحث

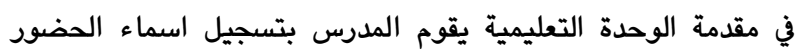
وتهيئة ألأدوات اللازمة .

عملية الاحماء وتقسم الى قسمين - الإحماء العام - الإحماء الخاص الاصدات التازئ النشاط التعليمي في هذا الجزء يتم تعليم الطلاب المهارة الحركية اذ يقوم الداء

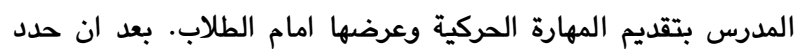

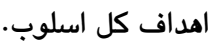

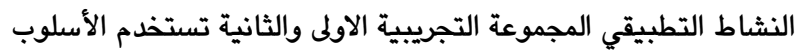
التنافسي المباشر ،والأسلوب التنافسي غير المباشر ويتم التطبيق

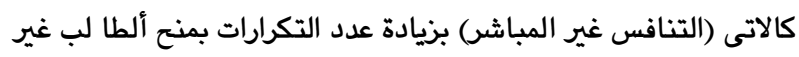

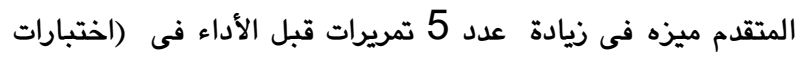

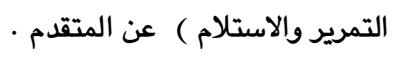

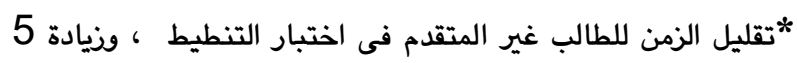
ثواتى للمتقدم ، اوأكثر

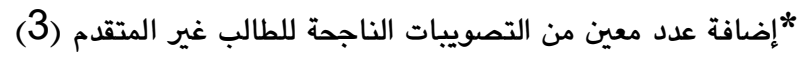

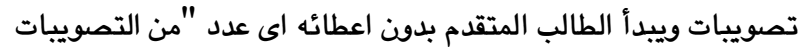

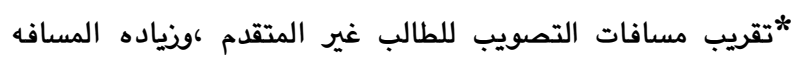

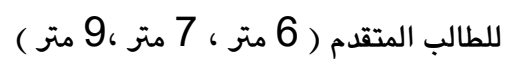

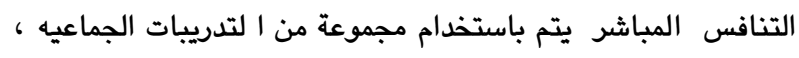
والالعاب الفريقيه ، التى تهدف الى تنمية المهارات الحركيه للطلبه

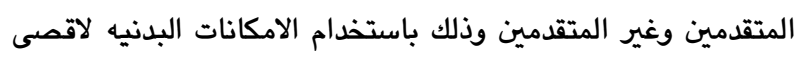

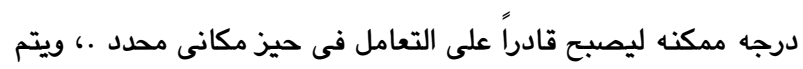
التطبيق باحد الوسائل الآتيه : التدريبات الثنائيه والجماعيه : يتم التمايز لكل طالب غير متقدم (ضعيف فى الاداء ) داخل مجموعته باضافة عدد من التكرارات مسبقا ، او بتقليل المسافه، او بتقليل زمن

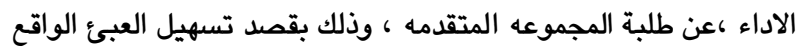
على الطلاب ذوى المستوى الضعيف غير المتقدمين ، وتصعيب العبئ

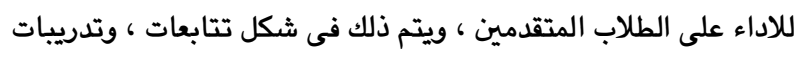
متدرجه من السهل الى الصعب .

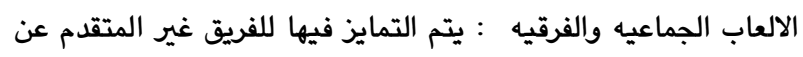

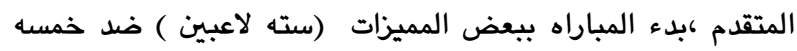

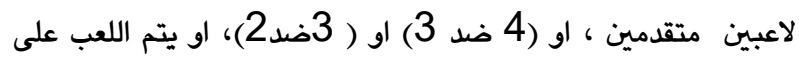
نصف الملعب فقط، ثم على الملعب كله. * اشتراك المعلم مع الفريق ( الضعيف ) غير المتقدم ضد المتقدم .

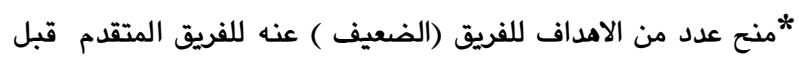

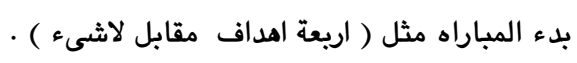

1- دلوفان اسعد نبي - ماجستير - كلية التربية الرياضية - جامعة دهوك

2-هلكت محمد صديق - ماجستير - كلية التربية الرياضية - جامعة دموك 3-هاريوان عابد طاهر - بكالوريوس كلية التربية الرياضية - جامعة دموك 11.3 التجربة الاستطلاعية الثانية للبرنامج التعليمي الخاص باسلوب التنافسي غير المباشر:

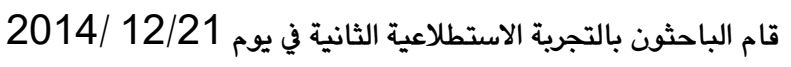
على عينة من مجتمع البحث مكونة من 10 طلاب وعلى مهارة الاستلام 1 بهدف: 1 - التاكد من مدى صلاحية البرنامج التعليمي للتطبيق. 3 - معرفة مدى استجابة الطلاب لتنفيذ محتويات الوحدة التعليمية المقترحة على وفق أسلوب التنافس غير المباشر .

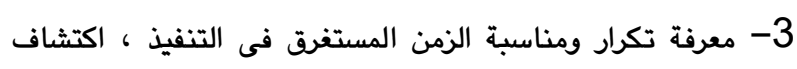
الصعويات التي تواجه الباحثون أثناء التطبيق كل جزء من أجزاء

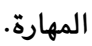
إعطاء صورة واضحة لمدرس المادة المكلف بما هو مطلوب منه ـ وكان من نتائج التجربة الاستطلاعية الأولى والثانية تكوين صورة واضحة لدى الباحثون ومدرس المادة على طبيعة العمل وكيفية التطبيق. 12.3 إجراءات التجربة :

تم إجراء القياسات القبلية للمجموعات الثلاثة بالنسبة للاختبارات

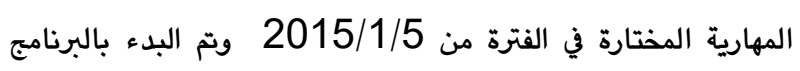

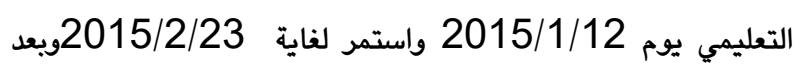
انتهاء تنفيذ البرنامج التعليمي تم تطبيق الاختبارات البعدية للمهارات

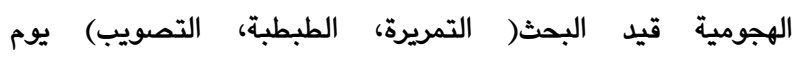
2015/2/25 للمجموعات الثلاثة .

\section{3 تنفيذ التجربة الرئيسية:}

بعد التكافؤ بين مجموعتي عينة البحث تم وضع برنامجين تعليميين

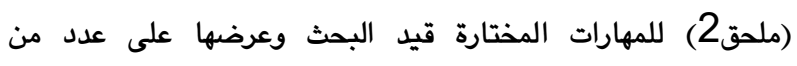

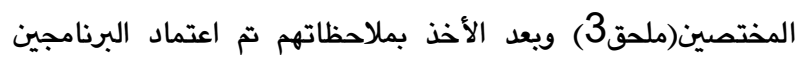
التعليميين للتطبيق بلغت مدة البرنامج 6 أسابيع ويواقع وحدتين

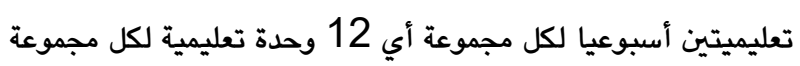

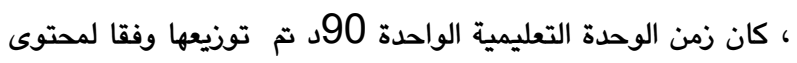

$$
\begin{aligned}
& \text { الوحدة على النحو التالي: } \\
& \text { المقدمة } 5 \text { د الند } \\
& \text { الإحماء } 15 \text { دـ } \\
& \text { النشاط التعليمي } 15 \text { دـ } \\
& \text { النشاط التطبيقي } 50 \text { د }
\end{aligned}
$$


14.3 المعالجات الاحصائية:

استخدم الباحثون الوسائل الاتية : 1 - 1 - 1 الوسط الحسابي

2- 2 - الانحراف المعياري 3- اختبار ( T ) للعينات المتساوية

4- ت تحليل التباين باتجاه واحد

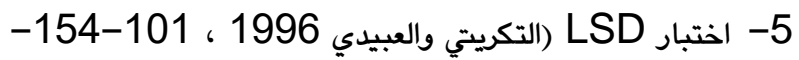
(310-271-209

تم معالجة البىانات بالاستعانة بنظام التحلىل الإحصائي ( spss )

4.عرض وتحليل النتائج ومناقشتها:

1.4 عرض وتحليل نتائج الاختبارين القبلي والبعدي للمجاميع

الثلاث

1.1 .4 عرض وتحليل و نتائج الاختبارين القبلي والبعدي للمجموعة التجريبية الاولى (الاسلوب التنافسي غير المباشر)

للاختبارات المهارية (الطبطبة ، التمرير ، التصويب):
* *سمح للفريق غير المتقدم باستخدام ایى عدد او نوع من التمريرات وموزعه فى جميع ارجاء الملعب ،بينما لا يسمح للفريق المتقدم الا باستخدام طول الملعب فقط بعدد محدد او نوع معين من التمريرات . * بسمح للفريق الضعيف باستخدام تنطيط الكره فى جميع ارجاء الملعب ويمنع الفريق المتقدم من استخدامها ـ يسمح للفريق غير المتقدم بتصويب الى نوع من التصويبات ،من مسافات قرييه من دائرة

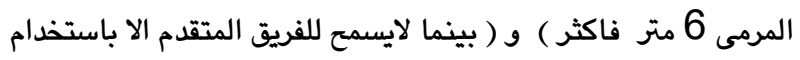

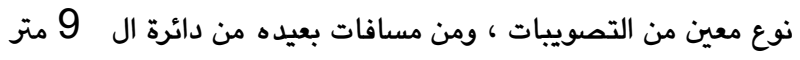
فاكثر ) ملحوظه يتم التقليل من الميزات التنافسيه للطلبه غير المتقدمين تدريجيا فى نهاية الدروس التعليميه (السابع : العاشر )ويتم التقييم النهائى بدون تمايز عند المقارنه بين المجموعات . . المجموعه الضابطه الثالثه : التي تستخدم العروض التوضيحيه (بدون تمايز تنافسى ) ويتم التطبيق بالطريقه التقليديه ، يؤدى الطلبه التدريبات المتنوعه الثنائيه ، والتتابعات ،والمسابقات ، ويقوم المعلم بالشرح اللفظى ،وعرض المتغيرات التى يشملها المقرد ،وتصحيح الاداء الخاطئ وفقا لقانون اللعبه ،والتوجيه ، والارشاد والتقييم . في نهاية الدرس يتم جمع الطلاب لاداء الجزء الختامي.

الجدول (3): يبين الوسط الحسابي والانحراف المعياري وقيمة (t) المحتسبة والجدولية للمجموعة التجريبية الاولى ( الاسلوب التنافسي غير المباشر )

\begin{tabular}{|c|c|c|c|c|c|c|c|}
\hline \multirow[t]{2}{*}{ مستوى الدلالة } & \multirow{2}{*}{ قالمحسوبة } & \multicolumn{2}{|c|}{ الاختبار البعدي } & \multicolumn{2}{|c|}{ الاختبار القبلي } & \multirow{2}{*}{\multicolumn{2}{|c|}{ لاحتائية الاختبار }} \\
\hline & & $\varepsilon_{-}^{+}$ & سَ' س س & $\varepsilon_{-}^{+}$ & سَ - س & & \\
\hline معنوي & 4.66 & 0.60 & 10,01 & 0.75 & 11.11 & زمن & الطبطبة \\
\hline معنوي & 6.09 & 2.86 & 12.28 & 2.64 & 8.92 & درجة & التمرير \\
\hline معنوي & 5.25 & 0.78 & 4.00 & 0.89 & 2.71 & درجة & التصويب \\
\hline
\end{tabular}

التمرير بلغت 6.09 وقيمة (t) المحتسبة لاختبار دقة التصويب بلغت 5.25 وعند مقارنة قيم (t) المحتسبة لكل اختبار مع قيمة (t) الجدولية تكون المحتسبة اكبر من الجدولية ولكل الاختبارات عند

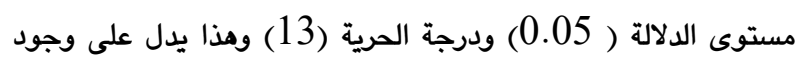
فروق معنوية ذات دلالة احصائية ولصالح الاختبار البعدي . 2.1.4 عرض وتحليل و نتائج الاختبارين القبلي والبعدي للمجموعة التجريبية الثانية (الاسلوب التنافسي المباشر)

للاختبارات المهارية (الطبطبة ، التمرير ، التصويب):
قيمة (t) الجدولية عند نسبة الخطأ > (0.05) وامام درجة الحرية $(2.16)=(13)$ من خلال جدول رقم (3) يمكن ملاحظة الاوساط الحسابية و الانحرافات المعيارية وقيمة (t) المحتسبة والجدولية للاختبارات الثلاثة ( الطبطبة ، التمرير ، التصويب ) للمجموعة الاولى ( الاسلوب التنافسي غير المباشر ) ولمعرفة فروق بين نتائج الاختبار القبلي والبعدي بهذه

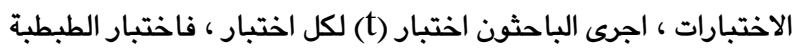
كانت قيمة (t) المحتسبة 4.66وقيمة (t) المحتسبة لاختبار دقة

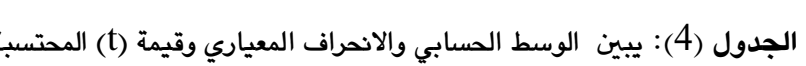

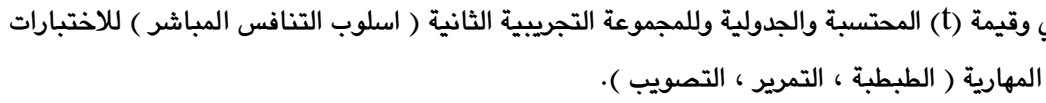

\begin{tabular}{|c|c|c|c|c|c|c|c|}
\hline \multirow[t]{2}{*}{ مستوى الدلالة } & \multirow[t]{2}{*}{ قيمة (t) المحسوية } & \multicolumn{2}{|c|}{ الاختبار البعدي } & \multicolumn{2}{|c|}{ الاختبار القبلي } & \multirow[t]{2}{*}{ الاحصائية } & \multirow{2}{*}{ الاختبار } \\
\hline & & $\varepsilon^{+}$ & سن & $\varepsilon^{+}$ & سَ - l - سَ & & \\
\hline معنوي & 2.94 & 0.83 & 9.99 & 1.02 & 10.39 & زمن & الطبطبة \\
\hline معنوي & 2.20 & 4.65 & 13.14 & 5.23 & 10.85 & درجة & التمرير \\
\hline معنوي & 5.08 & 0.78 & 5.00 & 0.57 & 4.21 & درجة & التصويب \\
\hline
\end{tabular}


التمرير بلغت 2.20 وقيمة (t) المحتسبة لاختبار دقة التصويب بلغت 5.08 وعند مقارنة قيم (t) المحتسبة لكل اختبار مع قيمة (t) الجدولية تكون المحتسبة اكبر من الجدولية ولكل الاختبارات عند مستوى الدلالة ( 0.05) ودرجة الحرية (13) وهذا يدل على وجود فروق معنوية ذات دلالة احصائية ولصالح الاختبار البعدي . 3.1 .4 عرض وتحليل نتائج الاختبارين القبلي والبعدي ولئي للمجموعة الثالثة (الاسلوب التقليدي) للاختبارات المهارية (الطبطبة ، التمرير ، التصويب):
قيمة (t) الجدولية عند نسبة الخطأ > (0.05) وامام درجة الحرية $(2.16)=(13)$ من خلال جدول رقم (4) يمكن ملاحظة الاوساط الحسابية و الانحرافات المعيارية وقيمة (t) المحتسبة والجدولية للاختبارات الثلاثة ( الطبطبة ، تمرير ، التصويب ) للمجموعة التجريبية الثانية ( الاسلوب التنافسي المباشر ) ولمعرفة الفروق بين نتائج الاختبار القبلي والبعدي بهذه الاختبارات ، اجرى الباحثون اختبار (t) لكل اختبار ، فاختبار الطبطبة كانت قيمة (t) المحتسبة 2.94وقيمة (t) المحتسبة لاختبار دقة الجدول (5): يبين الوسط الحسابي والانحراف المعياري وقيمة (t) المحتسبة والجدولية وللمجموعة الثالثة ( الضابطة ) للاختبارات المهارية ( الطبطبة ، التمرير ، التصويب ).

\begin{tabular}{|c|c|c|c|c|c|c|c|}
\hline \multirow{2}{*}{ مستوى الدلالة } & \multirow{2}{*}{ قيمة (t) المحسوية } & \multicolumn{2}{|c|}{ الاختبار البعدي } & \multicolumn{2}{|c|}{ الاختبار القبلي } & \multicolumn{2}{|c|}{ الوسائل الاحصائية } \\
\hline & & $\varepsilon_{-}^{+}$ & سَ & $\varepsilon+$ & سَ & & الاختبار \\
\hline معنوي & 2.72 & 0.83 & 11.38 & 0.98 & 12.17 & زمن & الطبطبة \\
\hline معنوي & 2.29 & 3.15 & 9.64 & 2.53 & 7.85 & درجة & التمرير \\
\hline معنوي & 6.03 & 0.87 & 4.00 & 0.92 & 2.64 & درجة & التصويب \\
\hline
\end{tabular}

الحصول عليها ، والمعروضة في الجداول الثلاث (3، 4 ، 5 5) والتي عولجت إحصائيا ظهر أن هناك فروقا ذات دلالة إحصائية بين الاختبارات القبلية والبعدية لمجموعات البحث الثلاثة في تعلم المهارات الهجومية بكرة اليد ولمصلحة الاختبار البعدي ويعزو الباحثون أسباب هذه الفروقات لدى عينة البحث الى فاعلية البرنامج التعليمي وما يحتويه كل برنامج تعليمي من عرض لمفردات المنهج وشرحها بطريقة ناجحة ،

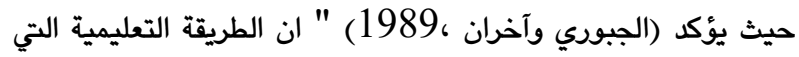
تتلاءم وقدرات الطلاب وإمكانياتهم الجسمية والعقلية والتي تمكن الطالب باختيار نواحي النشاط الملائم له وتحت اشراف وتوجيه المدرس تعمل على تحقيق أهداف الدرس " . وللتحقق من معنويات الفروق بين الاوساط الحسابية للمجاميع الثلاثة في الاختبارات المهارية ( الطبطة ، التمرير ، التصويب ) ثم استخدام صيغة تحليل التباين ( ff) للتعرف على دلالة الفروق بين المجموعات.
قيمة (t) الجدولية عند نسبة الخطأ > (0.05) وامام درجة الحرية (13)= (2.16) من خلال جدول رقم (5) يمكن ملاحظة الاوساط الحسابية و الانحرافات المعيارية وقيمة (t) المحتسبة والجدولية للاختبارات الثلاثة ( الطبطبة ، تمرير ، التصويب ) للمجموعة الثالثة (الضابطة ) ولمعرفة الفرقق بين نتائج الاختبار القبلي والبعدي بهذه

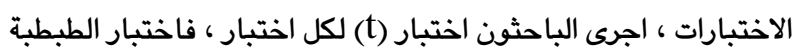
كانت قيمة (t) المحتسبة 2.72 وقيمة (t) المحتسبة لاختبار دقة التمرير بلغت 2.29 وقيمة (t) المحتسبة لاختبار دقة التصويب بلغت 6.03 وعند مقارنة قيم (t) المحتسبة لكل الاختبار مع قيمة (t) (t)

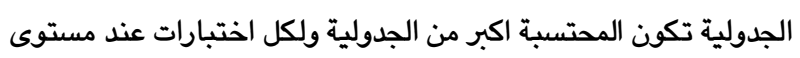
الدلالة ( 0.05) ودرجة الحرية (13) وهذا يدل على وجود فروق معنوية ذات دلالة احصائية ولصالح الاختبار البعدي ·

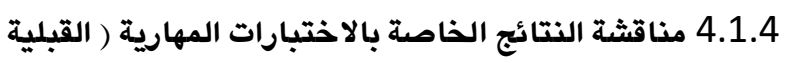
والبعدية ) لمجموعات البحث الثلاث: في ضوء النتائج التي تّ الجدول (6): يبين تحليل التباين بين المجموعات الثلاثة في الاختبارات البعدية للمهارات قيد البحث

\begin{tabular}{|c|c|c|c|c|c|c|}
\hline 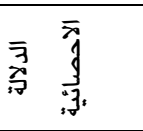 & 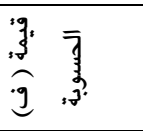 & 事沀 & 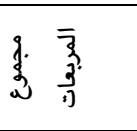 & درجات الحرية & المصادر الاختلاف & 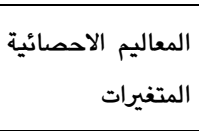 \\
\hline \multirow{2}{*}{ معنوي } & \multirow{2}{*}{14.70} & 8.67 & 17.34 & 2 & بين المجموعات & \multirow{2}{*}{ الطبطبة } \\
\hline & & 0.59 & 23.01 & 39 & داخل المجموعات & \\
\hline \multirow[b]{2}{*}{ معنوي } & \multirow{2}{*}{3.70} & 32.59 & 65.19 & 2 & بين المجموعات & \multirow{2}{*}{ التمرير } \\
\hline & & 8.79 & 342.92 & 39 & داخل المجموعات & \\
\hline \multirow[b]{2}{*}{ غير معنوي } & \multirow{2}{*}{2.82} & 3.71 & 7.42 & 2 & بين المجموعات & \multirow{2}{*}{ التصويب } \\
\hline & & 0.63 & 24.85 & 39 & داخل المجموعات & \\
\hline
\end{tabular}

قيمة (F) الجدولية عند نسبة خطأ > (0.05) ) وامام درجة الحرية من الجدول (6) بلغت قيمة (f) المحتسبة بين المجموعات الثلاثة في

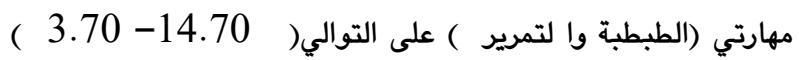
$\cdot(3.23)=(2.39)$ وهي اكبر من قيمة ( f ) الجدولية عند درجة الصرية 2- 39 ونسية 
ونسبة الخطأ 0.05البالغة 3.23 اي ان الفرق غير معنوي ولمعرفة اي المجموعات حققت مستوى تطور افضل فقد تمت معالجة معنويات الفروق بين الاوساط الحسابية بطريقة اقل فرق معنوي ( L.S.D) .

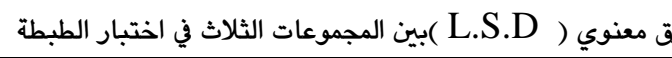

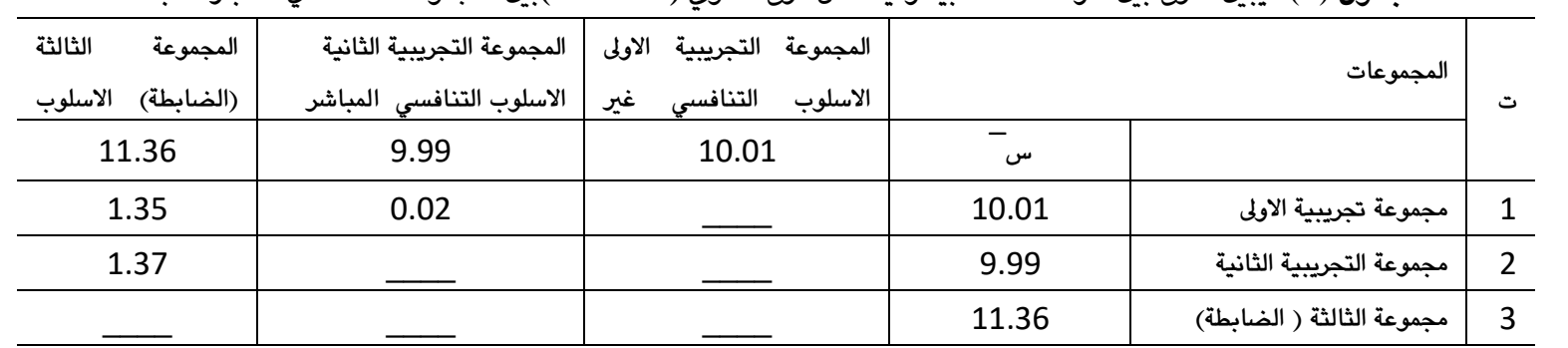

الخطأ 0.05 البالغة 3.23 اي ان الفرق معنوي · بينما بلغت قيمة ( المحتسبة بين المجموعات الثلاثة في مهارة ( التصويب ) بلغت

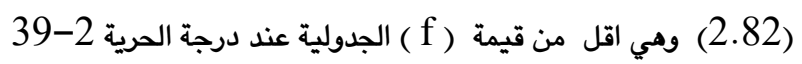
(1)

2 - ويلغ الفرق بين الاوساط الحسابية للمجموعتين الاولى ( الاسلوب

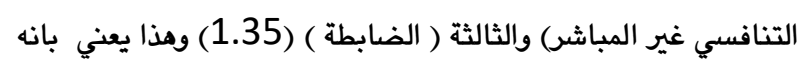
اكبر من قيمة اقل فرق معنوي ، لذا فالفرق بين المجموعتين معنوي

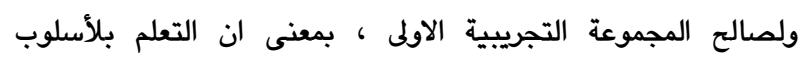
التنافسي غير المباشر افضل من الاسلوب التقليدي .

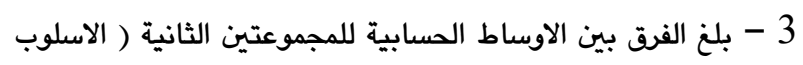
التنافسي المباشر) والثالثة ( الضابطة) ، (1.37) وهو اكبر من قيمة اقل فرق معنوي لذا فالفرق بين المجموعتين معنوي ولصالح التجريبية الثانية ( الاسلوب التنافسي المباشر ) ، بمعنى ان التعلم بلأسلوب التنافسي المباشر افضل من الاسلوب التقليدي.

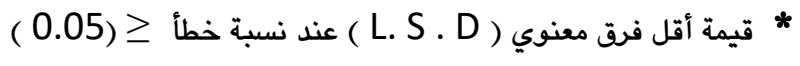

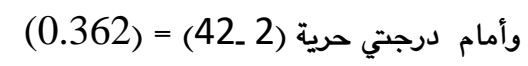
1- من الجدول (7) بلغت قيمة اقل فرق معنوي (0.362) وعند حساب فرق الاوساط بين المجموعات ظهر لدينا ان الفرق بين المجموعة التجريبية الاولى ( الاسلوب التنافسي غير المباشر ) والمجموعة التجريبية الثانية ( الاسلوب التنافسي المباشر) هو ( 0.02 ) وهو اقل من قيمة اقل فرق معنوي ، لذا فالفرق بين المجموعتين غير معنوي

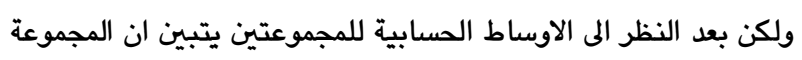
التجريبية الثانية افضل من المجموعة الاولى.

الجدول (8): يبين الفرق بين الاوساط الحسابية وقيمة اقل فرق معنوي ( L.S.D بين المجموعات الثلاث في اختبار التمرير

\begin{tabular}{|c|c|c|c|c|c|}
\hline المجموعة تجريبية الثالثة & المجموعة التجريبية الثانية & المجموعة التجريبية الاولى & \multicolumn{2}{|c|}{ المجموعات } & \\
\hline 9.64 & 13.14 & 12.28 & س- & & 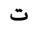 \\
\hline 2.64 & 0.86 & & 12.28 & المجموعة التجريبية الاولى & 1 \\
\hline 3.5 & & & 13.14 & المجموعة التجريبية الثانية & 2 \\
\hline 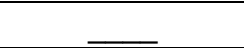 & 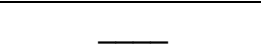 & 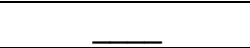 & 9.64 & المجموعة التجريبية الثالثة & 3 \\
\hline
\end{tabular}

3 - بلغ الفرق بين الاوساط الحسابية للمجموعتين الثانية ( اسلوب التنافس المباشر) والثالثة ( الضابطة) ، (3.5) وهو اكبر من قيمة اقل الاوساطل فرق معنوي لذا فالفرق بين المجموعتين معنوي ولصالح التجريبية

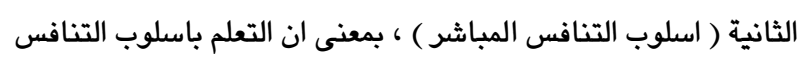
المباشر افضل من اسلوب التقليدي

4.2

من الجداول (7) (8) اظهرت وجود فروق معنوية لمهارتي( الطبطبة والتمرير) في التعلم ، وعند حساب قيمة اقل فرق معنوي ( (L.S.D) لترتيب المتوسطات الحسابية ظهر ان المجاميع قد ترتبت بنسق واحد

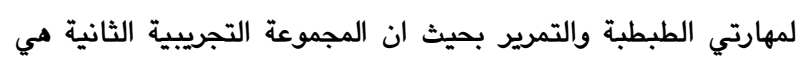

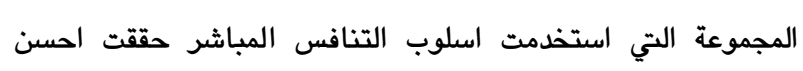

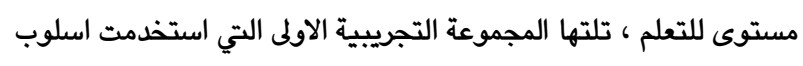
التنافس غير المباشر ثم المجموعة الضابطة الاسلوب التقليدي.
* قيمة أقل فرق معنوي ( L. S . D ) عند نسبة خطأ ج (0.05) )

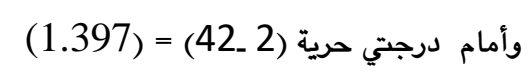

1 - من الجدول (8) بلغت قيمة اقل فرق معنوي (1.397) وعند حساب فرق الاوساط بين المجموعات ظهر لدينا ان الفرق بين المجموعة التجريبية الاولى ( الاسلوب التنافسي غير المباشر ) والمجموعة

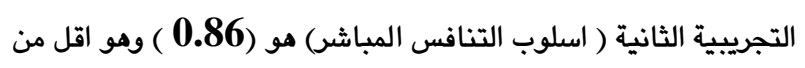
قيمة اقل فرق معنوي، لذا فالفرق بين المجموعتين غير معنوي ولكن بعد النظر الى الاوساط الحسابية للمجموعتين يتبين ان المجموعة التجريبية الثانية افضل من المجموعة الاولى. 2 - ويلغ الفرق بين الاوساط الحسابية للمجموعتين الاولى ( اسلوب التئي

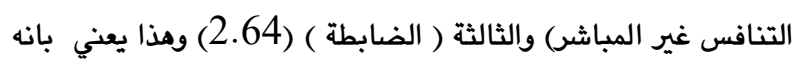
اكبر من قيمة اقل فرق معنوي ، لذا فالفرق بين المجموعتين معنوي

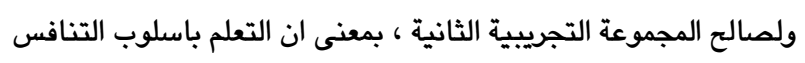
افضل من الاسلوب التقليدي. 
استخدمت الاسلوب العرضض التوضيحية ( التقليدي ) في تعلم بعض المهارات الهجومية بكرة اليد . 3- لم تظهر الاساليب الثلاثة ( التمايز التنافسي المباشر و التمايز ليدرة التنافسي غير المباشر و العرض التوضيحية ) اي فروق معنوية في تعلم مهارة التصويب ، الى ان الفرق بين الاوساط الحسابة كان اكثر في

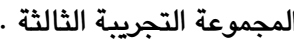
4- لاتوجد فروق ذات دلالة معنوية بين المجموعات الثلاثة في اختبارات مهارة التصويب الا ان الفرق بين الاوساط الحسابية كان اكثر في المجموعة التجريبية الثانية. 5.2

1- ادخال اسلوب التمايز التنافسي بانواعه في تعليم بعض المهارات الهجومية بكرة اليد. 2- التأكيد على اسلوب التنافس المباشر في التعلم لما فيه من نتائج

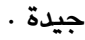
3- اجراء دراسات ويحوث اخرى باستخدام اساليب التنافس للالعاب

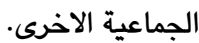

\section{6. - 6 - المصادر العربية و الاجنبية}

1- اسمر ، محمد خضر( 1998) : اثر اسلوب المنافسات والتغذية الراجحة

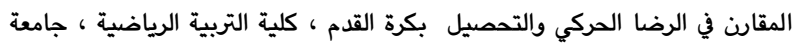
موصل اطرحة دكتوراه غير منشورة .

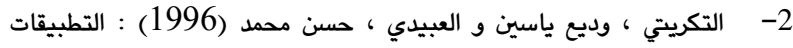
الاحصائية في بحوث التربية الرياضية ، دار الكتب للطباعة والنشر ، جامعة الموصل

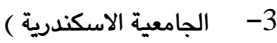
4 - جبر ، سعاد محمد ، ابو بكر، زينب محمد (1993) اثر استخدام التمايز

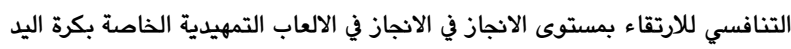

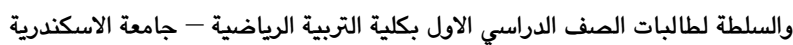

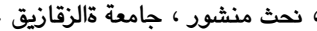
5- الجبوري ، عدنان واخران (1989) طرق تدريس التربية الرياضية والتعلم

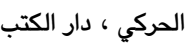
6- جرجس ، منير (2004): كرة اليد للجميع ، والتميز المهاري ، دار الفكر

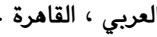

7 - الخياط ، ضياء قاسم (1995) : اثر استراتيجيتي التدريس بالاهداف والتغذية

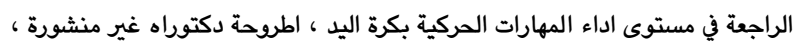

كلية التربية الرياضية ، جامعة الموصل.

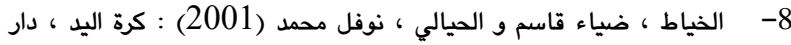
الكتب للطباعة ، جامعة الموصل 9- الخياط ،فداء اكرم (1997) : اثر استخدام اسلوبي التنافس الذاتي والمقان

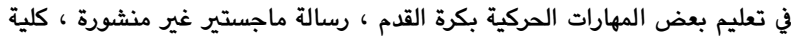

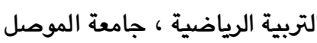

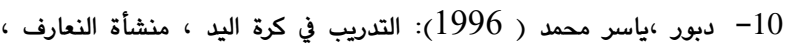

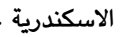

ومن هنا نستنتج ان مناك فرق معنوية لصالح الاختبار البعدي وللمجاميع الثلاثة ، مما يدل على ان البرنامج التعليمي الذي وضعه الباحثون قد ادى الى تطور هذه المهارات لدى افراد عينة البحث

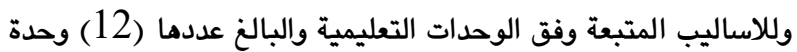
والتي راعى فيها الباحثون الشمولية والدقة والتشويق اثناء عملية التعلم ، ويعزوا الباحثون الى ان استخدام اسلوبي التنافسي المباشر و غير المباشرزاد من شدة الحافز في المجموعة الاولى والثانية بالشكل الذي جعلهم يؤدون المهارات بحماس كبير، كما ان اسلوب التنافس المباشر وغير المباشر وفر فرصة مثالية لاستثمار وقت القسم الرئيسي الخاص بتعلم وتطوير المهارات قيد البحث ـ ان عمل الطلاب على شكل مجاميع متقارية في المستوى ادى الى اهتمام الطلاب باثبات ذاته عن طريق

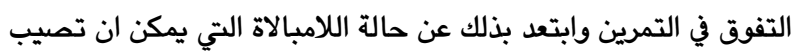
الطالب اثناء التنفيذ اذا كان زميله اقوى منه بدرجة كبيرة وحالة استخفاف اذ كان الزميل المنافس اقل منه بدرجة كبيرة ـ اذ يذكر (1997،Boniness) المستويات المهارية ينتج عنه اداء افضل بعكس اولئك الذين لا يكونون متقاربين في المستويات المهارية. ( Boniness، 1997، 125) . وكذلك يعزوا الباحثون سبب تطور المجموعة الضابطة ( الاسلوب التقليدي ) المتبع من قبل المدرس ( الشرح والعرض) له تاثير ايجابي في تطوير المهارات قيد البحث لملائمته لمستوى الطلاب، ومن ثم اداء الطلاب المهارات وتزويدهم بالتغذية الراجعة من خلال تصحيح الاخطاء في حالة حدوثها ، بالاضافة الى العدد المناسب من التكرارات جميع هذه العوامل ساعد في تعلم وتطوير الطلاب في مستوى الاداء المهاري ويشكلها الصحيح ، وهذا ما يتفق مع نتائج السائح ومعوض من ان هذا الاسلوب يعتمد على توجيهات وارثادات القائم بالتدريس ومن ثم الممارسة المتكرة من التلاميذ مع تصحيح الاخطاء بدون شك اتاح للتلاميذ فرصة لاكتساب خبرات تعليمية مما يؤثر بشكل مباشر على اداء التلاميذ . ( السائح، ومعوض ، 2002). ويعزوا الباحثون عدم وجود فروق معنوية في مهارة التصويب من القفز عاليا حيث تعد من المهارات الصعبة والتي تحتاج الى دقة وتركيز عالي اثناء ممارستها.

\section{5. الاستنتاجات والتوصيات}

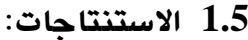
1- كان لاسلوبي ( التمايز المباشر وغير المباشر) واسلوب العروض التوضيحية ( التقليدي) تاثير ايجابي في تعلم بعض المهارات الهجومية

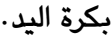
2- حققت المجموعة التجريبية الثانية التي استخدمت الاسلوب التنافسي المباشر مستوى افضل من المجموعة التجريبية الاولى التي استخدمت الاسلوب التنافسي غير المباشر والمجموعة الثالثة التي 


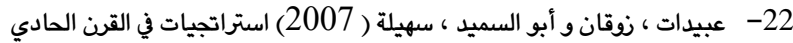

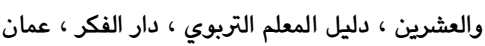

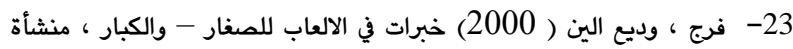

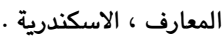

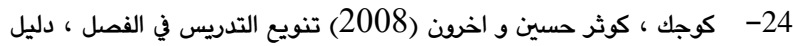

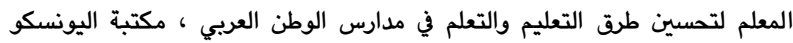

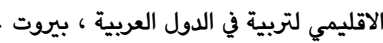

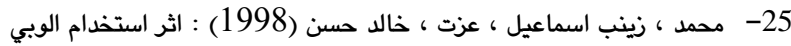

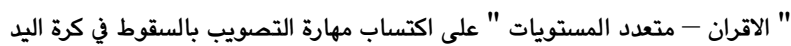

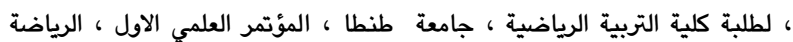

المصرية والعربية نحو آفاق العالمية ، جامعة حلوان

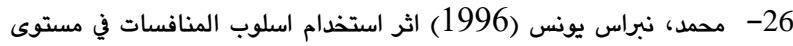

اداء بعض المهارات الحركية والاتجاهات بكرة اليد، رسالة ماجستير غير منشورة ،

كلية التربية الرياضية، جامعة الموصل.

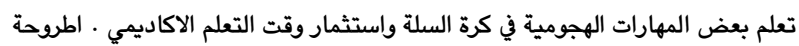

دكتوراة ، كلية التربية الرياضية - جامعة بغداد.

Symbosium for coaches. IHF. Portugal.

29- Rackner, H (1998) Handball running training

Session. European Handball Federation.

30- Robert, Scwarzkopf (1999): How to teach Handball to beginner. www.cohandball.com.

31- Boniness, Mohnses (1997): Teaching Middle School

Physical Education Huma Kinetics. Printing hall/ Australi.

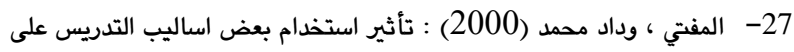

28- Peter, Kovacs (2002): Supstitution tactics ANDEBO.

11- الدوسكي ،سعدي عمر يوسف (2003) : تأثير استخدام اساليب مختلفة

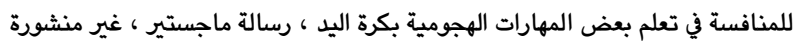

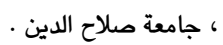

12 - رضا، محمد اسماعيل (2008) تأثير استخدام بعض اساليب تدريس التربية

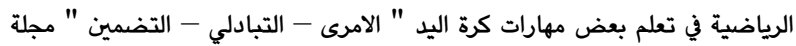
العلوم للتربية الرياضية ، العدد التاسع ، المجلد الاول.

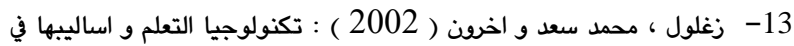
التربية الرياضية ، مركز الكتاب للنشر ، الطبعة الثانية ، القاهرة .

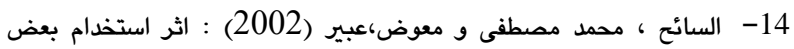
الوسائط المتعددة على الكفاءة التدريسية لطلاب المعلمين بكلية التربية الرياضية ، مجلة العلوم التربوية ، العدد الاول ، جامعة عين الشمس ل

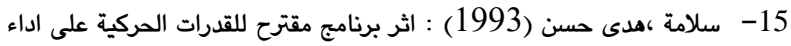
بعض مهارات كرة اليد للناشئات ، رسالة ماجستير غير منشورة ، كلية التربية الرياضية للبنات ، جامعة الاسكندرية . 16- الشافعي ، صبيحة عبدالحميد ( 2009) طرق واستراتجيات التدريس -

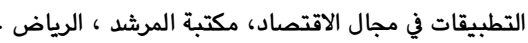

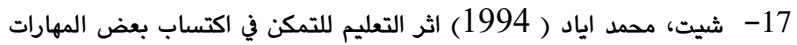

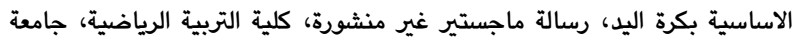

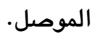
18- عبد السلام ، محمد فاروق (1999) تصميم بعض الجمل الحركية في صورة تنافسية لناشئى كرة اليد ، رسالة ماجستير غير منشورة ، كلية التربية الرياضية للبنين ، جامعة حلوان. 19- عبدالحميد ، كمال ، حسانين ، محمد صبحي (2002) رباعية كرة اليد الحديثة للمهارات الحركية ومراقبة مستوى الاداء ، مركز الكتاب للنشر ، القاهرة .

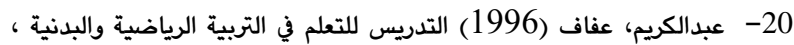

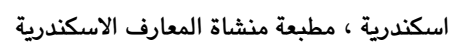

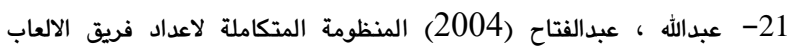
الجماعية لتحقيق نتائج ، المكتبة المصرية للطباعة ، الاسكندرية. الملحق (1)

استمارة استبيان لتحديد الاختبارات لقياس المهارات المحددة في البحث

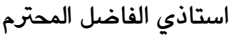

في النية اجراء البحث الموسوم تاثير إسلوبي التمايز التنافسي المباشر والغير مباشر في تعلم لبعض المهارات

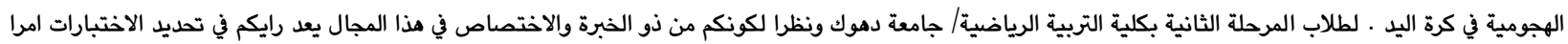

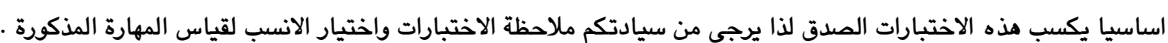
بالاضافة الى ذلك يرجى ترشيح اختبارات اضافية ترونها مناسبة للبحث ان وجدت شاكرين تعاونكم معنا الباحثون

\begin{tabular}{|c|c|c|c|}
\hline اختيار الاختبار & الاختبارات المرشحة & $ت$ & المهارة \\
\hline & الهدف من الاختبار المهارة في تمرير واستلام الكرة في اثناء الحركة على الحائط & -1 & \multirow[b]{2}{*}{ المناولة } \\
\hline & الهناولة الطويلة ودقة توجيه الكرة من مسافة (30 م) الاختبار: قياس مهارة المناولة الطويلة ودقتها & -2 & \\
\hline & الهدف من الاختبار: قياس الطبطة المستمرة في اتجاهات متعددة & -1 & \multirow[b]{2}{*}{ الطبطبة } \\
\hline & 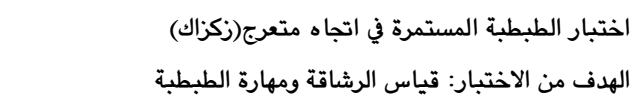 & -2 & \\
\hline
\end{tabular}


عزالدين، مؤيد كمال الدين و آخرون / مجلة العلوم الانسانية لجامعة زاخو، مجلد:5 ، العدد:3 ، ص 754- 767، أيلول - 2017.

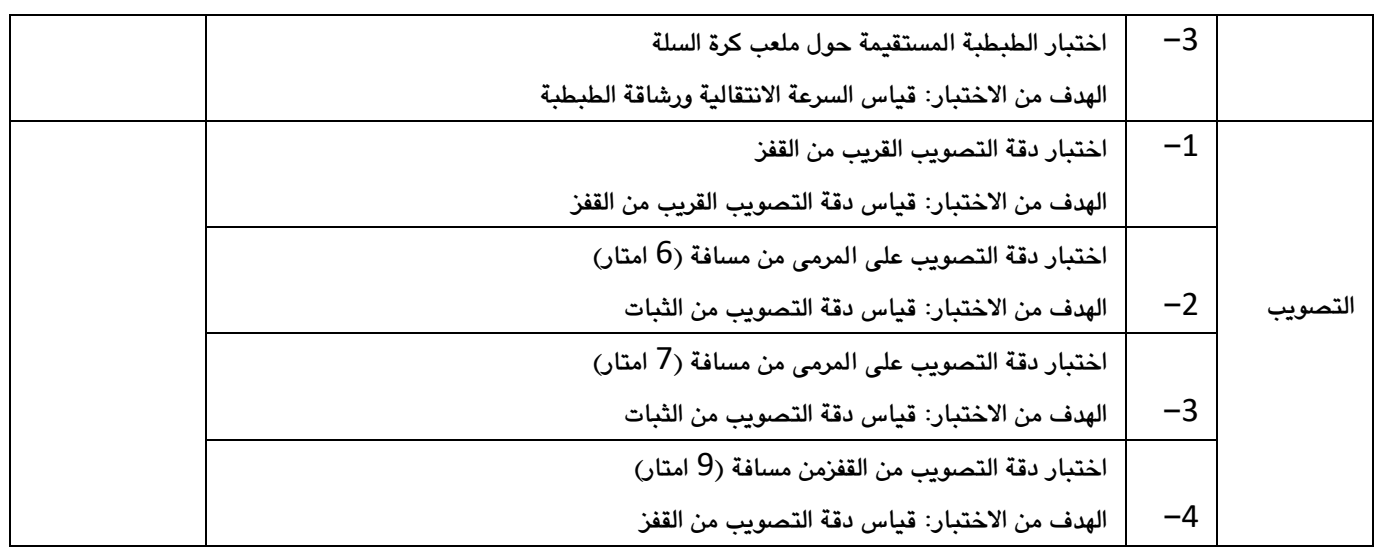

الملحق (2)

استبيان لجنة المحكمين والمختصين في البرنامج التعليمي

استاذي الفاضل المحترم

يقوم الباحثون اجراء البحث الموسوم تاثير إسلوبي التمايز التنافسي المباشر والغير مباشر في تعلم لبعض المهارات

الهجومية في كرة اليد لطلاب المرحلة الثانية بكلية التربية الرياضية بجامعة دهوك ـ. ولكونكم من ذوي الخبرة في هذا المجال يرجو الباحثون تعاونكم معهم في بيان مدى صلئ صلاحية

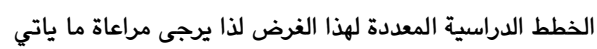
1- تدوين ملاحظاتكم حول صحة كل خطة ومدى تطابقها للخطوات العامة في تعليم المهارات الاساسية على وفق اسلوبي التمايز التنافسي المباشر والغير مباشر 2-2 - مدى صحة زمن انشطة وتمارين الوحدة التعليمية

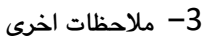

شاكرين تعاونكم معنا

وحدة تعليمية

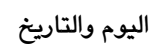
الاسلوب التدمايز التنافسي الغير مباشر الصف الثاني

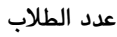
كرة يد - المناولة

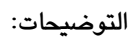
1- الكرات موجودة داخل مرمى كرة اليد 2- اعد الكرات بعد انتهاء من التطبيق الى مكانها 3- على الطالب مراعاة الدقة في الاداء الاحماء:

الاحماء العام: تهئية عامة لجميع اعضاء الجسم (5 د) الاحماء) الاحماء الخاص: تهئية تخدم القسم الرئيسي (10 د) المهمات

- قف ممسكا بالكرة امام الحائط ومرد الكرة واستلمها باستمرار من مسافة تتراوح ( 2- 3متر) على الحائط ( 5 د) - اعادة التمرين السابق من مسافات مختلفة ( 5 د) - اعادة التمرين السابق من ارتفاعات مختلفة ( 5 د)

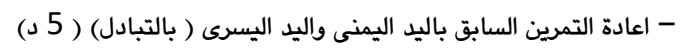
- قف انت وزميلك الواحد بعد الاخر على بعد ( 2- 3 متر) من الحائط وقم بتمرير الكرة على الحائط والعودة للخلف ليتقدم زميلك ويسلم الكرة ثم يمررها على الحائط (5 د د)

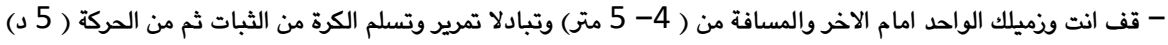

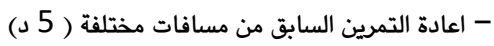

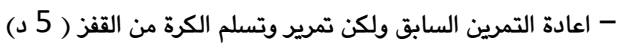

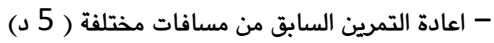
- قف انت وزميلك الواحد امام الاخر وتبادلا تمرير وتسلم الكرة بالتتابع ذهابا بتمريرات قصيرة وايابا بتمريرات طويلة ( 5 د) تقسم المجموعة إلى فريقين لعمل منافسة بينهما وإعطاء نقطة لكل فريق يمكن من أداء (8) مناولات من مستوى الراس، الإئ قبل أن يستحوذ عليها الفريق الآخر وذلك باستخدام نصف الملعب وحدة تعليمية 


$$
\text { اليوم والتاريخ }
$$$$
\text { الاسلوب التدمايز التنافسي المباشر }
$$$$
\text { الصف الثاني }
$$$$
\text { عدد الطلاب }
$$$$
\text { كرة يد - المناولة }
$$$$
\text { التوضيحات: }
$$$$
\text { 1- الكرات موجودة داخل مرمى كرة اليد }
$$

2- اعد الكرات بعد انتهاء من التطبيق الى مكانها 3- الطع الطالب مراعاة الدقة في الاداء

$$
\text { الاحماء }
$$

الاحماء العام: تهئية عامة لجميع اعضاء الجسم (5 د) الاحماء)

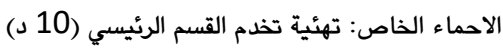
المهمات

- قف ممسكا بالكرة امام الحائط ومرد الكرة واستلمها باستمرار من مسافة تتراوح ( 3- 4متر) على الحائط ( 4 د)

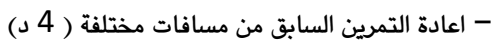

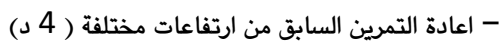

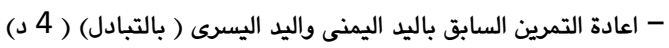
- قف انت وزميلك الواحد بعد الاخر على بعد ( 3- 4 متر) من الحائط وقم بتمرير الكرة على الحائط والعودة للخلف ليتقدم زميلك ويسلم الكرة ثم يمررها على الحائط (4 د)

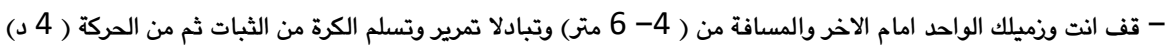

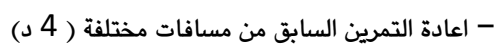

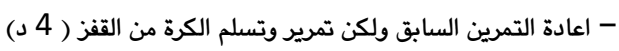

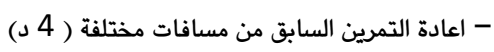
- قف انت وزميلك الواحد امام الاخر وتبادلا تمرير وتسلم الكرة بالتتابع ذهابا بتمريرات قصيرة وايابا بتمريرات طويلة ( 4 د)

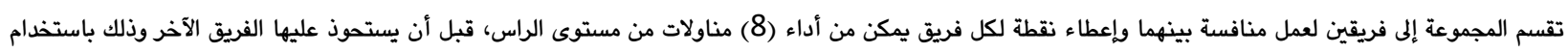
الملعب بالكامل

\section{الملحق (3)}

\begin{tabular}{|c|c|c|c|c|c|c|}
\hline \multicolumn{2}{|c|}{ 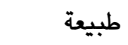 } & \multirow[t]{2}{*}{ عنوان الوظيفة الو } & \multirow[t]{2}{*}{ الاختصاص الدقيق } & \multirow{2}{*}{ القب العلمي } & \multirow[t]{2}{*}{ أسماء المختصين } & \multirow[t]{2}{*}{$ت$} \\
\hline 2 & 1 & & & & & \\
\hline * & * & جامعة زاخو & طرائق التدريس & استاذ مساعد & أ.م.د ـ احمد قاسم & 1 \\
\hline * & & سكول التربية الرياضية /جامعة دهوك & فسلجة علم التدريب & 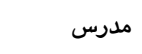 & ل د لمارسيل زيا & 2 \\
\hline * & * & سكول التربية الرياضية /جامعة دهوك & التعلم الحركي & مدرس & د. دممد حسن مصطفى & 3 \\
\hline$*$ & & سكول التربية الرياضية /جامعة دهوك & فسلجة علم التدريب & مدرس & د. آزاد احمد خالد & 4 \\
\hline & * & سكول التربية الرياضية /جامعة دهوك & 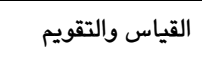 & 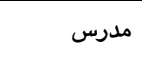 & د. جلال كمال محمد & 5 \\
\hline * & & سكول التربية الرياضية /جامعة دهوك & علم التدريب & مدرس & م .د زياد محفوظ & 6 \\
\hline * & * & سكول التربية الرياضية /جامعة دهوك & التعلم الحركي & مدرس & دـ ـ خالد محمد شعبان & 7 \\
\hline
\end{tabular}

أسماء السادة الخبراء و المختصين الذين وزعت عليهم استمارات الاستبيان لتحديد متغيرات الدراسة الماسة 


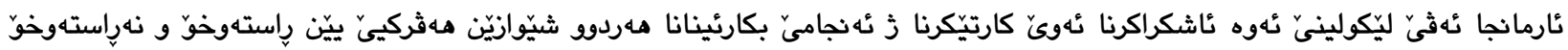

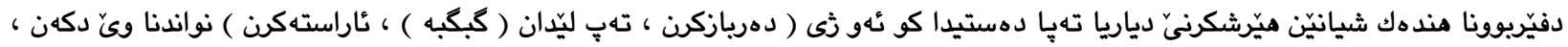

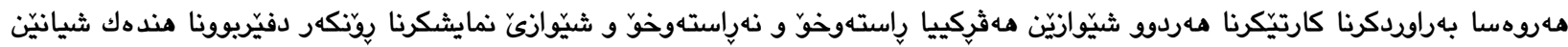

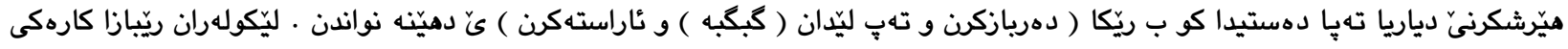

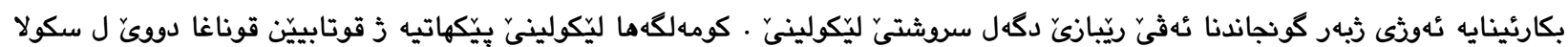
بهروهردا وهرزشى ل زانكويا دهوكيّ بو سالاً خواندنيّ ( 2014 - 2015 ) كو هزمارا وان ( 65 ) قوتابينه كو ل سهر سيّ يِّولان هاتينه

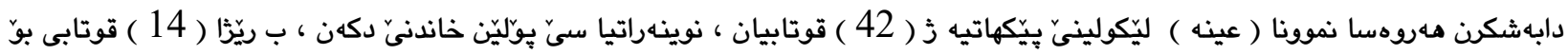

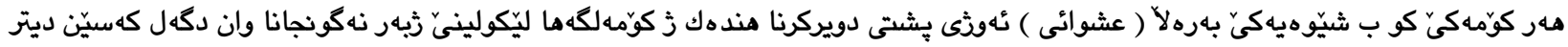

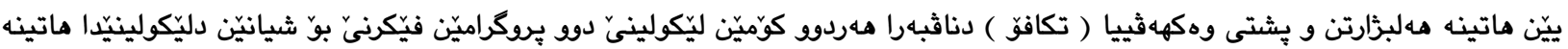

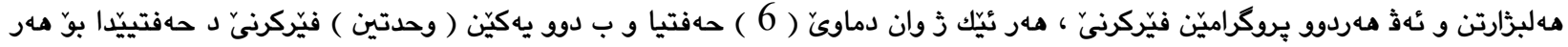

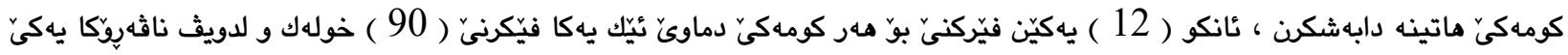

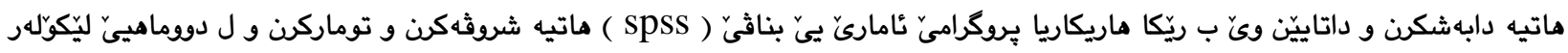
كه هشتينه ئهثان ئهن نجامان

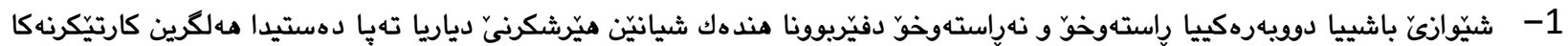

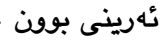

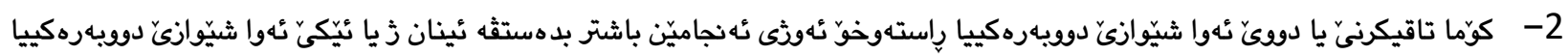

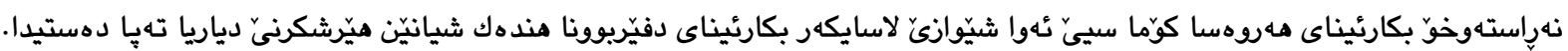

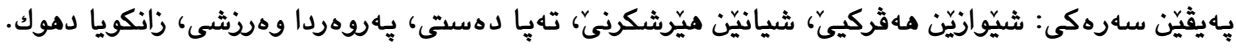

\section{The Effect of Direct and Indirect Competitive Differentiation Style in Learning Some Offensive Skills in Handball}

\section{Abstract:}

The research aims to figure out the effect of direct and indirect competitive differentiation style and showing explained show (classical) in learning some offensive skills in handball, and compare the results of both direct and indirect competitive differentiation and explained show (classical) styles in learning some offensive skills in handball. The researchers used thee experimental approach because the suitability to research. The community of research selected of second year students in school of Physical Education University of Duhok (2014-2015), they were 65 students divided to three groups. While the sample was consisted 42 students represented three groups, where each group consisted of 14 students, where chosen randomly after excluded some students because of homogeneity of research. After the homogeneity of research between the groups, two instructional programs were set up for the chosen skills, where the period of program was 6 weeks 2 times a week for 90 minutes. SPSS was used to analyze the data.

The researchers conclude:

1. The direct and indirect competitive differentiation styles (classical) have a positive effect on learning some offensive skills in handball.

2. The second experimental group that used the direct competitive differentiation styles better improvement than the first experimental group that used the indirect competitive differentiation styles and the third experimental group that used the classical styles in learning some offensive skills in handball.

Keywords: Methods of Competitive Differentiation, Offensive Skills, Handball, Faculty of Physical Education, University of Duhok. 